\title{
Value of a programmed investigation unit: an audit study
}

\author{
A P Moore, L D Blumhardt
}

\begin{abstract}
A programmed investigation unit (PIU) was set up in a regional neuroscience centre. Its effects were assessed by measuring the savings associated with one particular investigation, myelography, which accounted for $50 \%$ of admissions to the PIU. Substantial savings appear to be possible, but accounting techniques allow wide variations in the estimated amounts. These benefits have to be measured against improvements which occurred simultaneously on the other wards.
\end{abstract}

In 1986 a survey of myelography in our unit concluded that the cost of investigations could be considerably reduced by organisational changes. ${ }^{1}$ In an effort to streamline routine inpatient tests, a PIU was established in 1988. As myelography is applicable to a broad range of clinical conditions and the demand for this test remained stable throughout the previous study period, we decided to measure changes in the costs associated with myelography as an indicator of the impact of a PIU.

\section{Material and methods}

The centre has 116 general adult neurology/ neurosurgery beds on five wards. It is the only neurological service for approximately three million people in Merseyside and North Wales. The use and costs of myelography in the department were surveyed over a six month period in $1986-87 .{ }^{1}$ In 1988 the PIU was established and we repeated sections of the survey for a six month period, starting when the new unit opened.

A 24 bed general ward was converted from seven to five day use and split into two parts with eight beds allocated exclusively to the PIU. A state enrolled nurse was appointed to run the PIU. When she was on leave the PIU was closed. Patients requiring routine inpatient investigation or treatment could be admitted to the PIU for a maximum of two days (one overnight stay). Investigation requests were completed in advance by the consultant or senior registrar and the nurse in charge then coordinated admissions and prearranged all tests. The various departments (for example, radiology or neurophysiology) allocated quotas to the PIU for the more time consuming tests. House officers were required to check that the tests remained appropriate and that the patient was both fit for the tests on admission and had recovered before discharge. The results were discussed with the patient usually before discharge, but sometimes in a follow up clinic.

\section{Methods}

Following the method of Sandercock et al ${ }^{1}$ we identified prospectively all inpatients having myelography over a six month period. For each patient we recorded the ward, the consultant and the delay between admission and myelography. The duration of each inpatient stay was defined, as before, as the number of days from admission to myelography plus one day.

Costs were calculated as follows:

1 Total hospital costs (THC): Using 1986 prices, a hospital bed per day was estimated to cost $£ 130$. This included allowances for direct hospital costs, buildings, rates and services and depreciation of facilities. ${ }^{1}$ Much of the THC method reflects money spent which is not necessarily recoverable if patients are not admitted, since whole units would have to be closed and sold to realise the saving. It does, however, reflect efficiency savings transferable to other patients.

2 Direct hospital costs ( $D H C$ ): This includes allowances for nursing, drugs, medical sundries (dressings etc), meals and linen, but not secretarial time. Rates were calculated by the unit accountant for the seven day wards and for the PIU. The DHC method allows a rough calculation of money actually saved if patients are not admitted and is particularly affected by the bed occupancy rate because of relatively fixed overheads such as nursing costs. Comparisons of DHC estimates were therefore made a) using the actual bed occupancy rate (PIU 54\%, other wards $75 \%$ ) and b) using projected costs for a $75 \%$ occupancy rate for all wards, including the PIU.

Costs incurred in the radiography department were fixed at $£ 72.37$ per myelogram as in 1986 , to include materials used, capital depreciation and paramedical staff costs. The costs of buildings and services, medical staff time and paramedical overtime payments were not included in this section. 
Table Costs of myelography (at 1986 prices) during two six month surveys

\begin{tabular}{|c|c|c|c|c|c|c|}
\hline & \multirow{2}{*}{$\begin{array}{l}1986 \\
\text { Before PIU } \\
\text { (all seven } \\
\text { day wards) }\end{array}$} & \multicolumn{3}{|l|}{$1987-88$} & \multicolumn{2}{|l|}{ Change } \\
\hline & & $P I U$ & $\begin{array}{l}\text { Other } \\
\text { wards }\end{array}$ & Total & $\begin{array}{l}\text { Total } \\
\text { change }\end{array}$ & $\%$ change \\
\hline $\begin{array}{l}\text { Number of myelograms } \\
\text { Radiography costs }(£)^{\star} \\
\text { Inpatient days } \\
\text { Mean stay (days) }\end{array}$ & $\begin{array}{c}379 \\
28000 \\
1420 \\
3.75\end{array}$ & $\begin{aligned} 154 \\
11000 \\
294 \\
1.91\end{aligned}$ & $\begin{array}{c}243 \\
18000 \\
696 \\
2 \cdot 86\end{array}$ & $\begin{array}{l}397 \\
29000 \\
990 \\
2 \cdot 49\end{array}$ & $\begin{array}{l}+18 \\
+1300 \\
-430 \\
-1 \cdot 24\end{array}$ & $\begin{array}{l}+5 \\
+5 \\
-30 \\
-33\end{array}$ \\
\hline \multicolumn{7}{|c|}{$\operatorname{cosTs}(£)$} \\
\hline $\begin{array}{l}\text { A Total Hospital Costs } \\
\text { Accommodation }+ \\
\text { radiography }{ }^{\star} \\
\text { Average per patient }\end{array}$ & $\begin{array}{c}\text { bed day cost } f \\
212000 \\
560\end{array}$ & $\begin{array}{r}49000 \\
320\end{array}$ & $\begin{array}{r}108000 \\
445\end{array}$ & $\begin{array}{r}158000 \\
397\end{array}$ & $\begin{array}{l}-55000 \\
-163\end{array}$ & $\begin{array}{l}-25 \\
-29\end{array}$ \\
\hline \multicolumn{7}{|c|}{$\begin{array}{l}\text { B Direct Hospital Costs basis } \\
\text { bed day costs: PIU } £ 40 \text { ( } 54 \% \text { occupancy), other wards } £ 50 \text { ( } 75 \% \text { occupancy) }\end{array}$} \\
\hline $\begin{array}{l}\text { Accommodation }+ \\
\text { radiography }{ }^{\star} \\
\text { Average per patient }\end{array}$ & $\begin{array}{r}99000 \\
260\end{array}$ & $\begin{array}{r}23000 \\
149\end{array}$ & $\begin{array}{r}52000 \\
214\end{array}$ & $\begin{array}{r}75000 \\
196\end{array}$ & $\begin{array}{l}-24000 \\
-64\end{array}$ & $\begin{array}{l}-24 \\
-25\end{array}$ \\
\hline
\end{tabular}

^Rounded to nearest $£ 1000$.

\section{Results}

The pattern of admissions did not change between 1986-89. Compared with the 1986 survey, the average length of admission for myelography fell by $33 \%$ (PIU $49 \%$, other wards $24 \%$ ) (table). Despite an increase of $5 \%$ in the number of myelograms performed, 430 inpatient days were saved (30\% reduction) even though the PIU was closed for three weeks due to leave requirements. Only one of 308 patients stayed on the PIU more than the scheduled two days during the six month survey. Of the 154 myelogram patients, three were transferred to other wards because of post myelogram complications and $29(19 \%)$ to neurosurgical wards for operation. Twenty six had additional planned investigations during their PIU admission (excluding blood and CSF tests).

Total Hospital Costs (THC): The overall "saving" of $£ 55000$ in the study period of 28 weeks translates to an annual "saving" of $£ 101000$. The cost of myelography for all cases fell by $33 \%$ (PIU $45 \%$, other wards $21 \%$ ), a direct reflection of the reduction in length of stay.

Direct Hospital Costs (DHC): The PIU occupancy rate of $54 \%$ gave a bed per day a cost of $£ 40$. For the other wards the occupancy rate was $75 \%$ and bed per day cost $£ 50$. This gave a calculated overall saving of $£ 23000$ over 28 weeks, or $£ 42000$ annually. The cost per patient fell by $25 \%$ overall (PIU $42 \%$, other wards $18 \%$ ).

\section{Discussion}

Variations in accounting practice allow considerable leeway in cost estimates. Direct comparison with the 1986 survey was achieved by using the same criteria for entry, duration of stay and costs. Much of the $£ 101000$ annual THC "savings" identified then have been realised. Unless beds or buildings are closed, however, such savings largely amount to beds freed for other uses.

The DHC estimate of $£ 43000$ annually is a better indicator of money not spent on myelography. It is largely composed of staffing costs, especially nursing. These form an impor- tant overhead so that the bed occupancy rate becomes a critical factor in estimating direct costs. If the PIU occupancy had been $75 \%$, as for the other wards, then greater savings would have been made. For patients on the PIU, the bed per day cost would have fallen to $£ 31$ and the average cost of myelography to $£ 130$, a $50 \%$ reduction. Overall savings would be even greater if a proportion of the extra PIU patients came from those who would otherwise have been admitted to the traditional (more expensive) wards.

This audit revealed a flaw in the hospital's collection of bed occupancy figures which missed short stay patients and initially gave a rate of $26 \%$ for the PIU. After correction, the PIU was still relatively underutilised during the survey (54\% vs $74 \%$ on the other wards) and higher PIU occupancy in future should lead to further savings.

There are several reasons for the higher efficiency of the PIU. The pre-booking of tests and other administrative tasks performed by the PIU nurse reduces work for house officers and registrars. Departments may be better able to schedule their routine work and take account of staff availability. Patients were almost never admitted to the PIU to find that the scheduled tests could not be completed. One further potential benefit was that myelogram request forms were made out by the consultant or senior registrar initiating the test, rather than a third party. Communication errors revealed by the previous audit ${ }^{1}$ should be less likely to occur and there should be fewer unnecessary or inappropriate tests.

We were surprised that the duration of admissions on the other wards for myelography fell by $24 \%$. One factor may have been the increased efficiency in use of medical time, perhaps as a "spin-off" effect from the PIU example. It should be noted, however, that the average length of stay for all neurological and neurosurgical patients admitted to the neuroscience unit also fell by $19 \%$ (from $9 \cdot 7$ to 7.9 days) between April 1987 and September 1989. Although such effects are difficult to quantify, house officers were probably able to deal more promptly with other admissions and 
there were fewer unpredictable demands on the radiologists.

Possible disadvantages of a PIU include effects on the outpatient clinics, which we did not assess. Senior staff spent more time filling in forms. More outpatient reviews were probably required as the consultant was less likely to see the patient in hospital with all the results available. Although most patients are pleased to spend a shorter initial time in hospital even with the possibility of a readmission, for some a single longer admission may be preferable: careful patient selection for PIU admission is important. The need to readmit some patients for surgery may also incur extra costs, but these were not examined.
This audit study suggests that considerable improvements in efficiency and real savings were associated with the introduction of a PIU. It remains possible that similar cost reductions could be achieved without a PIU by pre-booking inpatient investigations, but a PIU provides a formal system with administrative help which greatly simplifies such forward planning.

We thank the PIU nurse Cathy Erskine and Lawrence Murphy, the unit accountant. This study was supported by MRHA Research Grant 527.

1 Sandercock PAG, Roberts MA, Blumhardt LD. A prospective audit of the use and costs of myelography in a regiona neuroscience unit. J Neurol Neurosurg Psychiatry 1989, 52:1078-84. 